\title{
DITADURA, GÊNERO E RACISMO NO TEMPO PRESENTE: DIÁRIO DE UM ENCONTRO DOCENTE
}

\author{
Nashla Dahás Gomozias \\ Universidade Federal do Rio de Janeiro (UFRJ), Brasil \\ E-mail: nashladahas@hotmail.com \\ ORCID: https://orcid.org/0000-0001-5384-4715 \\ Adriana Silva Teles Boudoux \\ Universidade do Estado da Bahia (UNEB), Brasil \\ E-mail: adrianaboudoux@yahoo.com.br \\ ORCID: https://orcid.org/0000-0002-8631-9869
}

Data de recebimento: $14 / 02 / 2020$

Data de aprovação: 25/03/2020

DOI: https://doi.org/10.30612/frh.v22i39.12567

\begin{abstract}
Resumo: Este artigo é resultado do minicurso de título semelhante ministrado por ocasião do II Seminário de Ensino de História das Escolas Públicas da Grande Florianópolis cujo tema geral foi "Os desafios do ensino de história em tempos de conservadorismo e neoconservadorismo". O evento ocorreu em meados do mês de agosto de 2019, no Instituto Estadual de Educação, no Centro de Florianópolis, e teve como alvo principal os professores da rede pública da educação básica da capital catarinense e de cidades circunvizinhas. $\mathrm{O}$ intuito é fazermos uma apresentação da dinâmica de nossa experiência de contato com o grupo de docentes inscritas(os), destacando os objetivos de nossa proposta para o curso, nossa percepção da reação e respostas do grupo; a incorporação das demandas das professoras(es) presentes e os impasses que surgiram na interação entre o projeto de minicurso e o processo de sua realização. Esperamos, com isso, contribuir para levantar questões sobre os usos, impasses e abordagens, no cotidiano docente, de temas-trauma e categorias de análise mais evidentemente emergentes desde os anos 2000, quais sejam, ditadura civil-militar, gênero, racismo e interseccionalidade.
\end{abstract}

Palavras-chave: Ditadura, Gênero, Racismo, História do Tempo Presente, Ensino de História.

\section{DICTATORSHIP, GENDER AND RACISM IN THE PRESENT TIME: DIARY OF A TEACHER MEETING}

Abstract: This article is the result of a short course with a similar title given during the "II Seminário de Ensino de História das Escolas Públicas da Grande Florianópolis", whose general theme was "The challenges of teaching history in times of conservatism and neoconservatism". The event took place in the middle of august 2019, at the State Institute of Education, in the Center of Florianópolis, and had as its main target the teachers of the public network of basic education in the capital of Santa Catarina and surrounding cities. The aim is 
to make a presentation of the dynamics of our experience of contact with the group of registered teachers, highlighting the objectives of our proposal for the course, our perception of the reaction and responses of the group; the incorporation of the demands of the teachers present and the impasses that arose in the interaction between the mini-course project and the process of its realization. We hope, with this, to contribute to raise questions about the uses, impasses and approaches, in the classroom, of "trauma-themes" and categories of analysis most evident emerging since the 2000s, namely, civil-military dictatorship, gender, racism and intersectionality.

Keywords: Dictatorship, Gender, Racism, History of the Present Time, History Teaching

\section{DICTADURA, GÉNERO Y RACISMO EN LA HISTORIA RECIENTE DIARIO DE UNA REUNIÓN DE PROFESSORES}

Resumen: Este artículo es el resultado de un mini curso con un título similar dado durante el "II Seminário de Ensino de História das Escolas Públicas da Grande Florianópolis", cuyo tema general fue "Los desafíos de enseñar historia en tiempos de conservadurismo y neoconservadurismo". El evento tuvo lugar a mediados de agosto de 2019, en el Instituto Estatal de Educación, en el Centro de Florianópolis, y tuvo como objetivo principal a los docentes de la red pública de educación básica en la capital de Santa Catarina y las ciudades circundantes. El objetivo es hacer una presentación de la dinámica de nuestra experiencia de contacto con el grupo de maestros registrados, destacando los objetivos de nuestra propuesta para el curso, nuestra percepción de la reacción y las respuestas del grupo; la incorporación de las demandas de los maestros presentes y los callejones sin salida que surgieron en la interacción entre el proyecto del mini curso y el proceso de su realización. Esperamos, con esto, contribuir a plantear preguntas sobre los usos, impases y enfoques, en el aula, de "temas de trauma" y categorías de análisis más evidentes emergentes desde la década de 2000, a saber, la dictadura civil-militar, el género, el racismo y Interseccionalidad.

Palabras clave: dictadura, género, racismo, historia reciente, enseñanza de la historia.

\section{Considerações iniciais}

Este artigo é resultado do minicurso de título semelhante ${ }^{1}$ ministrado pelas duas autoras por ocasião do II Seminário de Ensino de História das Escolas Públicas da Grande Florianópolis cujo tema geral foi "Os desafios do ensino de história em tempos de conservadorismo e neoconservadorismo". O evento ocorreu em meados do mês de agosto de 2019, no Instituto Estadual de Educação, no Centro de Florianópolis, e teve como alvo principal os professores da rede pública da educação básica da capital catarinense e de cidades $1 \quad$ Originalmente, o minicurso se chamou "Historiografia, Ensino de História e Espaço Público. Ditadura e Racismo no Tempo Presente". A questão de Gênero tornou-se imprescindível no decorrer do encontro como se verá mais à frente neste artigo. A adaptação para esta publicação suprimiu debates mais estritamente historiográficos, gerando a alteração no título. 
circunvizinhas. O intuito é fazermos uma apresentação da dinâmica de nossa experiência de contato com o grupo de docentes inscritas(os), destacando os objetivos de nossa proposta para o curso de oito horas de duração, divididas em duas manhãs; nossa percepção da reação e respostas do grupo; a incorporação das demandas das professoras(es) presentes e os impasses que surgiram na interação entre o projeto de minicurso e o processo de sua realização. Esperamos, com isso, contribuir para levantar questões sobre os usos e abordagens de categorias emergentes a partir dos anos 2000, e mais destacadamente na década seguinte, na intersecção entre os campos do Ensino de História, da Historiografia e do Espaço Público ${ }^{2}$ tais como gênero, racismo, interseccionalidade e ditadura civil-militar. O texto terá a forma de um diário de anotações acerca de um momento singular em nossas trajetórias, pois que marcado pela imprevisibilidade e pela diversidade do contato com professoras(es) mais e menos experientes no magistério, mas igualmente submetidos a uma conjuntura presente de crescimento social e político neoconservador com desdobramentos institucionais e subjetivos evidentes na área das Humanidades ${ }^{3}$.

\section{Uma proposta em movimento}

$\mathrm{Na}$ ementa submetida ao evento, prevíamos a apresentação e discussão acerca da demanda social contemporânea por intervenções e discursos históricos como um fenômeno próprio à imbricação de temas-trauma como ditadura, gênero e racismo, verificando as características de proximidade, atravessamento e afastamento da produção de narrativas a esse respeito nos campos da historiografia, do Ensino de História e do Espaço Público. Ou seja, nossa ideia era discutir abordagens de sala de aula para temas que optamos por chamar de temas-trauma, considerando a virada epistemológica que passou a condicionar a leitura dos fenômenos históricos dentro de um panorama ético e político, o que não significa, evidentemente, uma moralização da história. Trata-se, como afirma o professor de teoria literária, Marcio Seligmann-Silva, do contexto de um reenquadramento da história do ponto de vista da memória e das políticas da memória (BRAGA, 2018) que considera a

2 A expressão Espaço Público designa aqui um conjunto de locais de circulação de ideias e opiniões, mais ou menos tradicionais, desde a grande mídia às novas redes sociais, entre outras esferas e sociabilidades.

3 A esse respeito, sugerimos consultar as sucessivas notas de repúdio produzidas pela Associação Nacional de História (ANPUH) e divulgadas no site da instituição a exemplo de https://anpuh.org.br/index.php/2015-01-20-00-01-55/noticias2/noticias-destaque/item/5523-anpuh-brasil-notade-repudio (Último acesso em 5 de junho de 2020). 
singularidade da memória dos traumas em sociedades pós-catástrofe, genocídio e terrorismo de Estado.

No campo do Ensino de História, esta discussão tem sido abordada na perspectiva dos temas sensiveis, definidos como aqueles que trazem à tona questões "socialmente vivas" e “controversas', "carregadas de emoções", “difíceis", por se constituírem como questões abertas para a sociedade e se relacionarem à violação de direitos humanos (GIL e EUGÊNIO, 2018). Assim, ao propor um minicurso sobre racismo, gênero e ditadura no tempo presente, nos situávamos politicamente contra a reprodução de injustiças históricas, sobretudo as que tentaram silenciar as narrativas de determinados grupos, a exemplo de negras(os) e indígenas.

Dialogar com as(os) docentes sobre esses temas e as possibilidades de sua inserção nas aulas de História se constituiu um grande desafio para nós: por estarmos vivendo um momento em que professores comprometidos com estas questões estavam sendo acusados de doutrinadores pela extrema direita em ascensão; e porque éramos duas professoras acadêmicas, uma carioca e uma nordestina, dispostas a dialogar com professores(as) catarinenses, que lidam com isso em seu fazer cotidiano no chão da escola, partindo, portanto, de lócus de enunciação diferenciados. Era preciso insistir na necessidade de trabalharmos com documentos históricos e com a elaboração de argumentos como possibilidade de tornar a sala de aula um espaço aberto ao conhecimento crítico e plural. Sobre o segundo, propomos atividades dialógicas. Mais do que ensinar como fazer, a ideia era aprender/conhecer a partir das experiencias e diálogo com as(os) docentes. Na busca desta simbiose, organizamos as atividades em dois momentos: o primeiro seria uma exposição/dialogada a partir de referenciais teóricos sobre o tema e o segundo compreenderia a realização de uma oficina com usos de documentos previamente selecionados com vistas a explorar as suas potencialidades para o ensino de história.

Sem entrar nos detalhes de nossa programação 'subvertida' pelo processo real do contato com a pluralidade de experiências trazidas pelo grupo, vale mencionar que pretendíamos, como ponto alto dos trabalhos, realizar uma oficina de fontes cujo objetivo consistia em proporcionar 'materialidade' à transversalidade dos temas abordados. Para tanto, utilizaríamos intervenções de historiadores(as) na imprensa, livros didáticos, trechos de filmes, além da exemplificação de 'lugares de memória' que permitissem apreender narrativas sobre conteúdos escolares a partir de categorias como gênero, racismo, violência de Estado e etc. 
Basicamente, foi com essas ideias e instrumentais que iniciamos nosso encontro. Todo o percurso, entretanto, acabou adquirindo novos contornos. Segue nosso diário de bordo.

\section{Saberes localizados, docentes no centro da história}

Partindo do conceito de saberes localizados proposto por Donna Haraway (1995, 2009) iniciamos nosso encontro-minicurso com perguntas gerais presentes tanto nos meios acadêmicos e-ou militantes quanto nos âmbitos de senso comum como as redes sociais: "O que ocorreu no ano de 1964?”. “O que é raça?”. “O que os termos ditadura, raça e gênero têm em comum?" Estas questões foram propostas para que pudéssemos partir dos conhecimentos prévios dos/das docentes, mas especialmente para que pudéssemos localizá-los e problematizá-los. De acordo com a crítica de Haraway, o modelo epistemológico ocidental predominante frequentemente separa objetividade de subjetividade, porém a primeira constitui sempre uma visão parcial, ou seja, parte de um corpo humano em determinadas circunstâncias, circuitos de violência e afetos. Tal como afirma Juliana Góes (2019), trata-se de corpos localizados territorial, social e temporalmente:

Assim, Haraway propõe uma visão corporificada, que produz um conhecimento corporificado e, como tal, localizado e parcial. A corporificação do conhecimento implica em se posicionar, ou seja, compreender que o saber é produzido por corpos e reconhecer a localização social e política que estes ocupam na estrutura. A objetividade é, então, um conhecimento localizado (GÓES, 2019).

Inicialmente, esse instrumental teórico foi pensado para ajudar nossa exposição do tema, mas, ao fim e ao cabo de sua realização e elaboração coletiva, ele nos ajudou a perceber a importância das respostas do grupo em suas especificidades, e da necessidade de incorporação de uma multiplicidade de leituras imprevistas acerca dos eventos históricos que pretendíamos abordar, especialmente, porque nem todas corresponderam às expectativas de uma visão informada pela cultura de direitos humanos.

Em todo o percurso, pareceu-nos que há uma oscilação da postura docente. De um lado, notamos uma segurança de narrar a história "de fora dela" segundo critérios mais tradicionais de distanciamento e objetividade, garantindo certa segurança e autoridade de professoras(es). De outro, observamos em suas falas um esforço em tornar a história mais "viva" inserindo as(os) estudantes - a partir de fontes do cotidiano, do diálogo com discursos históricos da imprensa, músicas contemporâneas e redes sociais, ou ainda incluindo as 
memórias familiares e das comunidades vizinhas à escola. Mas esta opção, de certa forma, obriga a(o) docente a também se colocar na história, se posicionar, ser um sujeito de sua narrativa, o que ainda vem causando desconforto e sensação de fragilidade. Acreditamos que encontros em que as experiências podem ser compartilhadas, além dos necessários investimentos públicos na formação docente, são caminhos de superação deste impasse.

Todas(os) inscritas(os) nos pareceram familiarizados com as palavras "golpe", para lidar com o ano de 1964, e "cor da pele"।"preconceito", para lidar com a questão racial, e "mulheres"।"diferença"।"diversidade" quando se tratava de pensar o gênero. Independente do conteúdo estrito das respostas, nos interessava avaliar o grau de dúvidas, a hesitação e o interesse diante das questões propostas, bem como sua relação com as experiências cotidianas de cada um(a). Observamos, assim, que a maior dificuldade estava em correlacionar os temas. Mais ou menos informadas(os) por perspectivas acadêmicas, e de acordo com suas histórias pessoais, de forma geral, as(os) participantes demonstraram uma lacuna quando se tratou de cruzar as formas de violência e as categorias de pensamento que as vêm nomeando. Esse dado nos levou a insistir, de maneira não programada, - como veremos mais à frente - na discussão sobre interseccionalidade. Sem a compreensão deste conceito não seria possível seguir pensando em um ensino de História que se quer contrário a todas as formas de silenciamento e opressão.

\section{O tempo presente como abordagem histórica}

Antes de prosseguir, contudo, concluímos breve apresentação acerca da noção de tempo presente que aparece no título do minicurso. A ideia era discutir esse campo de pesquisas como uma maneira de entender e operar a disciplina histórica em seus variados graus de aprofundamento. Segundo nosso entendimento, a História do Tempo Presente configura também uma forma de lidar com a produção de conhecimento e está atravessada pelas modalidades sociais de sentir e pensar a violência de Estado, ou seja, a violência estrutural. Especificamente, destacamos pressupostos da HTP que (assim consideramos) podem contribuir para a formação de professoras(es) no trabalho de sala de aula em torno de temas como ditadura, gênero e racismo.

A primeira questão que colocamos consistiu na contemporaneidade do não contemporâneo segundo uma perspectiva historiográfica francesa (ROUSSO, 2016; DELACROIX, 2018). Nossa ideia era estimular intervenções a respeito do questionamento 
dos tempos históricos tal como a historiografia ocidental vem apresentando desde o século XIX. Em outras palavras, gostaríamos de provocar o público de nosso minicurso no que concerne ao entendimento da divisão do tempo em passado (encerrado), presente (atual) e futuro (mais ou menos previsível conforme a pedagogia do passado no presente).

Dessa experiência, constatamos que a imbricação no mesmo presente de séries temporais diferentes tornou-se corrente no vocabulário das(os) docentes nas salas de aula. Entretanto, e de maneira, geral, podemos afirmar que a maneira como o tema é evocado passa majoritariamente pela demonstração de continuidades históricas ligadas ao racismo, ao machismo e à estigmatização de populações pobres e periféricas. Do ponto de vista da formação de professoras(es), consideramos que esse viés de abordagem apresenta pontos positivos e também fragilidades. Sem dúvida, a visibilidade das continuidades da violência estrutural em sala de aula torna a história-disciplina mais real e pertinente ao cotidiano das turmas em sua grande multiplicidade de vivências. Contudo, ressaltamos também o risco de que as especificidades dos períodos históricos, regimes políticos e formações culturais sejam subvalorizadas e o conhecimento histórico acabe por reforçar noções naturalizadas do presente e geralmente expostas através de formulações como "sempre foi assim".

O segundo ponto de nossa apresentação acerca da HTP foi a politicidade dos temas como ditadura, racismo e gênero em estreita vinculação com a esfera pública e os movimentos sociais (Franco, 2018). Um dos exemplos escolares que utilizamos para tratar desta questão foi o da ditadura civil-militar brasileira (1964-85). Apresentamos abordagens que circularam no espaço público, assim como as maneiras com que historiadoras(es) responderam em circunstâncias políticas determinadas. Para começar, retomamos o ano de 2004, aniversário de quarenta anos do golpe, como momento (talvez) originário das controvérsias públicas acerca da nomenclatura referente ao próprio golpe. Como ressaltou Mariana Joffily em artigo publicado dez anos depois, no cinquentenário da ruptura democrática, um sentido que se consolidou naquele ano de 2004 e que dialoga mais com narrativas produzidas na imprensa do que com a produção de pesquisas na área acadêmica, ainda que mantenha o rigor científico em sua formulação, é o do apoio civil de setores da sociedade:

Esse questionamento, proposto em 2000 por Daniel Aarão Reis, inspirado pelas historiografias russa sobre o stalinismo, alemã sobre a cumplicidade de setores da sociedade com o nazismo e francesa sobre Vichy, buscou explicar a longevidade da ditadura, impossível sem alguma base de sustentação social, e os traços autoritários disseminados na sociedade brasileira. A população civil aparece nessa discussão não apenas como a elite condutora 
do golpe, ou como sua "massa de manobra" e sim como atores oriundos das classes médias e populares que aderiram voluntariamente à ditadura e a apoiaram mesmo em práticas autoritárias (JOFFILY, 2018).

Assim que, para todos os efeitos, o "golpe" passou a se chamar "golpe civil-militar", a ditadura tende também a tornar-se "ditadura civil-militar". Tal caracterização consistiu, em grande medida, em espécie de denúncia política do esquecimento ou do encobrimento da participação civil nos acontecimentos que resultaram na deposição do presidente João Goulart em 1964, e na instauração da ditadura, bem como em sua institucionalização. Trata-se de questão sensível uma vez que amplia as responsabilidades pela ditadura, dos militares apenas, para os setores civis da sociedade, com destaque para os "sujeitos comuns".

Outro exemplo bastante explícito é o do trocadilho "ditabranda", utilizado por setores conservadores e alçado ao status de categoria explicativa pelo jornal Folha de São Paulo em seu editorial de 17 de fevereiro de 2009. Utilizando números sugeridos pelos arquivos dos próprios organismos de repressão da ditadura, a expressão procura negar ou relativizar a existência do terror de Estado no Brasil (BAUER, 2011). A chancela acadêmica foi conferida a essa interpretação pelo historiador Marco Antônio Villa que ocupou o espaço da grande imprensa para difundir essa leitura do passado recente. Segundo Villa, a ditadura se realizou "à brasileira", ou seja, de maneira mais branda que as contemporâneas no Cone Sul: "Não é possível chamar de ditadura o período 1964-1968 (até o AI-5), com toda a movimentação político-cultural. Muito menos os anos 1979-1985, com a aprovação da Lei de Anistia e as eleições para os governos estaduais em 1982” (VILLA, 2009).

O debate, vale dizer, suscitou a intervenção de diversos sujeitos e instituições entre intelectuais, pessoas públicas, ativistas e militantes. O próprio editor do caderno Brasil do jornal Folha de São Paulo, Fernando de Barros e Silva afirmou que:

O mundo mudou um bocado, mas "ditabranda" é demais. O argumento de que, comparada a outras instaladas na América Latina, a ditadura brasileira apresentou níveis baixos de violência política e institucional parece servir, hoje, para atenuar a percepção dos danos daquele regime de exceção, e não para compreendê-lo melhor (SILVA, 2009 apud JOFFILY, 2018).

De parte das(os) participantes do minicurso que oferecemos, o debate sobre a participação civil no golpe e na ditadura de 1964 não pareceu muito surpreendente ainda que o termo civil-militar, não fosse utilizado de maneira corrente seja nas salas de aula de séries em que o conteúdo programático inclui o período, seja em termos de formação pessoal. 
As respostas mais comuns entre as que recebemos quando pedimos que as professoras(es) se expressassem sobre a politicidade dos temas como parte do ofício histórico nos dias atuais foram as seguintes: (a) insistimos no uso e crítica de fontes em sala de aula como o aprendizado mais básico e importante para tratar de História; (b) é preciso discutir em sala de aula a questão da verdade em História; (c) frequentemente, nos dedicamos a desconstruir narrativas da grande imprensa sobre o golpe e a ditadura; (d) uma das grandes dificuldades é que as(os) alunas(os) trazem, muitas vezes, informações equivocadas sobre golpe e ditadura que ouviram de familiares ou pessoas muito próximas; (e) equiparamos as narrativas sobre a repressão na ditadura com a violência estatal da polícia militar sobre pessoas negras e pobres atualmente para que a turma perceba a dinâmica injusta e histórica da violência de Estado.

Consideramos, pois, que o tratamento do tema no referido minicurso - ademais de coletivizar impasses vividos individualmente por professoras(es) e alunas(os) em salas de aula -, produziu também interessantes deslocamentos acerca da própria noção da disciplina História que, cada vez mais, se interessa por dialogar com os diversos discursos sobre a história que circulam no espaço público. Uma das questões que verificamos como pouco discutida coletivamente ocorre da seguinte maneira: a solução encontrada por muitas(os) profissionais para lidar com a pluralidade de discursos históricos, mantendo-se a especificidade da produção historiográfica de narrativas, recai sobre a reiteração do cientificismo, do rigor teórico e metodológico das práticas de produção de conhecimento histórico. Entretanto, esse mesmo argumento é criticado quando o discurso parte para outras paragens igualmente politizadas como a crítica do conhecimento europeizado e de sua objetividade que tende a invizibilizar as mulheres como sujeitos da história, entre muitos outros exemplos. Novamente, momentos de reflexão conjunta parecem necessários para a consolidação progressiva de argumentos consistentes a respeito do fazer histórico.

\section{Ditadura e racismo, possibilidades de abordagens}

Encerramos a primeira parte do minicurso fazendo circular documentos da "Divisão de Segurança e Informações do Ministério da Justiça para ser difundido entre SNI/AC RECISA - CENIMAR - CIE", órgãos da repressão vigentes durante a ditadura e citados no Relatório de Pesquisa da Comissão da Verdade do Rio de Janeiro intitulado Colorindo 
memórias e redefinindo olhares: Ditadura Militar e Racismo no Rio de Janeiro. Em dois desses documentos, lê-se:

Existe no BRASIL, já há alguns anos, embora com certa raridade, a intenção velada do movimento subversivo em suscitar o problema da discriminação racial, com o apoio dos órgãos de comunicação social. [...] Pela análise realizada pelos Órgãos de Informações, em 1971, conclui-se que indivíduos inescrupulosos e ávidos, para aumentarem as vendas de seus jornais ou revistas, e outros, principalmente por estarem ligados ou viverem na subversão ou terrorismo, estavam constantemente, difundindo boatos e notícias que exploravam o assunto, [...] (Arquivo Nacional: AC ACE 78482/74, CNF, I/I. Relatório, 2011, p.7)

"Da mesma forma, para as organizações subversivo-terroristas o acirramento de antagonismos raciais é um meio útil a seus propósitos. A publicação clandestina "INDEPENDÊNCIA OPERÁRIA", porta-voz do MR-8 (Movimento Revolucionário 8 de Outubro), em seu n.28, edição de Jul. 77, instiga claramente a revolta racial com "palavras de ordem" como "contra a educação racista", "contra a discriminação racial" e "por uma autêntica democracia racial". Preconiza, também, a introdução, nos currículos escolares, da disciplina "História do Negro", além da criação de um periódico noticioso exclusivamente da "Comunidade Afro-brasileira" (Informação 580/19/AC/78:Disponível no Arquivo Nacional: AC ACE 109622/76, CNF, I/4, p. 17. 11, Relatório, 2011, p.9)

Nossa ideia era apresentar aspectos do racismo como base ideológica - pouquíssimo discutida - da ditadura implantada em 1964, que dispõe de boa quantidade de documentos oficiais que podem ser utilizados em salas de aula. Infelizmente, a pequena duração do minicurso não nos permitiu aprofundar as apreciações das(os) inscritas(os) sobre essa questão. Mas, sem dúvida, a utilização destes documentos permitiu expandir horizontes temáticos que consideramos mais interseccionais. Problematizamos esta dimensão tomando como um dos referenciais o trabalho da pesquisadora e ativista Carla Akotirene, para quem o termo consiste em uma categoria teórica que rastreia múltiplos sistemas de opressão, articulando raça, gênero e classe e permitindo instrumentalidade teórico-metodológica à conjugação estrutural do racismo, capitalismo e cis-hétero-patriarcado (Akotirene, 2018). Partindo da necessidade de explorar este conceito, decidimos aprofundá-lo na manhã seguinte do encontro com as(os) docentes.

\section{Interseccionalidade, um desafio docente}

A segunda parte do minicurso - mais prática do que a anterior - foi dedicada aos desafios do ensino de História no tempo presente. Inicialmente, em sintonia com 
estudiosas(os) da área, tais como Pereira e outras (2015, p. 35), entendíamos como primordiais:

[...] o desafio do atendimento das demandas dos grupos identitários - seu direito ao passado; o desafio da própria memória, em uma época na qual tudo se guarda e tudo se arquiva, por receio do esquecimento e da imprevisibilidade do futuro; o desafio das histórias contadas fora da escola, nas mídias ou na internet, que criam relatos sobre o passado e concorrem com o discurso professoral.

Entretanto, sem abrir mão desse entendimento, foi preciso ampliá-lo, incorporando a perspectiva interseccional que, conforme dito anteriormente, se apresentou como uma lacuna e mais um importante desafio a ser enfrentado. Tínhamos ciência de que tal problema não seria resolvido em algumas horas de conversa, porém resolvemos aproveitá-las, por mínimas que fossem, para sensibilizar as(os) docentes sobre esta questão. Para isso, nos inspiramos na obra da pesquisadora, teórica e escritora Grada Kilomba, intitulada Memórias da plantação. Episódios de racismo cotidiano (2019). Consideramos apropriada àquela formação de professores, a abordagem da autora voltada ao desmonte da normalidade do racismo, com destaque para os aspectos de violência e de trauma vividos por homens e mulheres negras, colocados(as) como a(o) Outra(o) da História, sendo representados como selvagens e inferiorizados.

A questão de gênero foi incontornável, talvez por nós, ministrantes do curso sermos mulheres, assim como a maioria das/dos nossas(os) cursistas. E, principalmente, porque as maiores dificuldades relatadas diziam respeito às reações, em sala de aula, ao que consideramos avanços dos movimentos feministas e identitários no nosso país como, por exemplo, a visibilidade das mulheres como sujeitos fundamentais da história; o direito ao nome social em instituições públicas; o crescimento do discurso social contra o machismo; bem como a percepção desta violência como estrutural e alimentada pelo sistema socioeconômico capitalista. Porém, ao adotarmos a abordagem interseccional, assumimos que a discussão sobre gênero, assim como sobre classe, idade, e todas as outras formas de classificação social, não podem prescindir da discussão sobre raça e racismo.

Iniciamos com definições de raça, racismo, e gênero em falas livres. De nossa parte, as referências que nos informam adotam as seguintes definições: raça é uma construção social forjada no contexto colonial/moderno pelos europeus para classificar as populações em superiores e inferiores, brancos e não brancos, respectivamente, sujeitando estes últimos a formas extremas de exploração social e permanente violência; a racialização dos sujeitos 
produz o racismo, que aprisiona e violenta o sujeito como Outra/o, subordinada(o) e exótica(o). Segundo Achille Mbembe (2018, p. 12) "o negro e a raça têm sido sinônimos no imaginário das sociedades europeias", representando uma ficção que, ao reduzir o corpo negro à cor da pele, como atributo de não humanidade, produziu inúmeras catástrofes e crimes incalculáveis. Por meio do racismo, nega-se o sujeito negro, tanto física (corpos) quanto subjetivamente (ação do sujeito no mundo social). Em última instância, racismo pode ser considerado como a construção da diferença segundo valores hierárquicos que afirmam a supremacia branca (KILOMBA, 2019, p. 76). Sua forma no Brasil adquiriu contornos estruturais, integrando as dinâmicas social e politica; institucionais, operando nas universidades, escolas, mídias e empresas nas quais se reproduzem os privilégios das pessoas brancas colocando as/os negras(os) em desvantagem; e cotidianos através da reiteração da infantilização, invisibilização, animalização, e erotização dos sujeitos negros(as). De acordo com Grada Kilomba, racismo é ainda o trauma de pessoas negras produzido pelo contato com o mundo branco: “é a dor de estar preso na ordem colonial”, no tempo presente.

No que diz respeito a categoria de gênero, segundo nossa formação pessoal e acadêmica, o célebre artigo da historiadora J.Scott, Gênero: uma categoria útil de análise histórica (1995), publicado originalmente em 1986, havia sido o ponto de partida. Naquele momento de publicação no Brasil, em meados da década de 1990, apenas cinco anos após o fim oficial da ditadura civil-militar (1964-85), a dualidade entre sexo e gênero - sendo o primeiro um dado incontornável da natureza e o segundo, uma consequência lógica da cultura -, permanecia ainda enraizada socialmente, inclusive, no pensamento político das esquerdas em seus variados matizes, como mostram trabalhos acadêmicos (DUARTE, 2014; GREEN, 2014). Scott propôs um conceito de gênero como percepção determinada, hierarquizada e cristalizada sobre as diferenças sexuais. A historiadora não negava a existência de diferenças entre corpos sexuados, mas seu interesse recaia sobre os sentidos culturais atribuídos a essas diferenças que as posicionavam dentro de relações de poder hierárquicas. Assim, a forma engessada como se pensava os gêneros conformava todo o tipo de relações de poder subaltenizando as mulheres, além dos tipos de comportamentos e corpos que não correspondessem àquela dualidade atemporal entre homens e mulheres. A utilidade analítica de gênero estaria, por assim dizer, na possibilidade de retirar "masculino e feminino", "homens e mulheres", "sexo e gênero", etc; do campo das categorias fixas e universais. Embora esta tenha sido uma leitura importante que marcou o nosso percurso formativo, o debate atual também nos colocou diante de outras questões. A potência do feminismo negro 
no tempo presente, por exemplo, nos apontou para a indissociabilidade das categorias raça, classe e gênero, entre outras.

Diante disso, incluímos a discussão sobre interseccionalidade, conceito inaugurado por kimberlé Crenshaw no final da década de 1980 e que, desde então, passou a ser aprofundado e pautado pelas intelectuais negras estadunidenses (AKOTIRENE, 2018). Ressaltamos que se trata de uma teoria também nascida de movimentos sociais e políticos, de militantes e ativistas, incluindo as feministas negras brasileiras, como Lélia Gonzalez, que já compartilhavam esta perspectiva, antes mesmo da introdução do termo. Oferecemos ao grupo de professoras(es) referências para pesquisa pessoal e aprofundamento, como Sueli Carneiro (2019), e discutimos a expressão que a autora vem utilizando: "enegrecendo o feminismo", para ressaltar a participação das mulheres negras na história do feminismo brasileiro.

A menção ao trabalho da filósofa, ativista e escritora Sueli Carneiro (2019) nos ajudou na apresentação e diálogo sobre o conceito proposto, uma vez que a autora problematiza a concepção universalista da categoria "mulher" que por muito tempo predominou no feminismo branco, o qual não incorporou as demandas específicas das mulheres negras subalternizadas não apenas pelas relações de gênero, mas também de raça e classe. E esse nos pareceu um ponto fundamental, pois, as(os) professoras(es) da rede de ensino de Florianópolis lidam cotidianamente com a diversidade de classes entre suas alunas e alunos, especialmente, no interior daquilo que se convencionou chamar de classes médias. Ademais, um dos discursos que afeta negativa e diretamente o avanço das políticas públicas de direitos dos grupos subalternizados no Brasil frequentemente afirma que a luta social contra a desigualdade de classes e contra a discriminação advinda desta diferença seria suficiente para proporcionar, na escola, um ambiente de igualdade de ensino-aprendizagem. Em contraposição a este discurso reducionista, e em consonância com o ponto de vista interseccional, compartilhamos com as(os) docentes a necessidade de pensar raça, gênero e classe como inseparáveis, visto que, uma só pessoa pode sofrer essas múltiplas opressões. É importante lembrar, como ressalta Kilomba (2019, p. 99), que não se trata de camadas singulares e sobrepostas de opressão, mas de entrecruzamentos que, no caso das mulheres negras, se configura como "racismo genderizado", uma forma única, "estruturada por percepções racistas dos papéis de gênero".

Com base nessas discussões, procuramos provocar a sensibilidade do grupo para a interação estrutural de eixos da subordinação como racismo, machismo, homofobia, etc. $\mathrm{Ou}$ seja, nossa tarefa consistia em mostrar os perigos da invisibilidade e da insensibilidade 
interseccional nas salas de aula. Para tanto, utilizamos a metodologia inspirada na obra já citada de Grada Kilomba, perguntando ao grupo: Quem tem falado nas aulas de história? O que tem sido falado? Quem não tem falado? O que não tem sido falado? Quem tem sido representado como sujeito histórico e em quais circunstâncias?

O resultado foi bastante inesperado, não havendo nada próximo de um consenso quanto às respostas. Embora as falas das(os) professoras(es) fossem unânimes em afirmar que têm inserido as questões de gênero e raça nas aulas de História, percebemos que este trabalho ainda se dá de modo pontual. Alguns disseram, inclusive, ser esta uma cobrança, em sala de aula, de grupos de estudantes consideradas(os) politizadas(os) com desdobramentos considerados positivos tais como o questionamento colocado aos professores(as) a respeito de sujeitos históricos como mulheres, homossexuais, negras(os), etc. Ao mesmo tempo, relataram a presença daqueles para os quais há pouca discussão e preparo, ou que provocam a intimidação de colegas de turma. Ou seja, a abordagem de tais temas é uma demanda dos próprios estudantes, tanto para os que são sujeitos sociais e que se vêem como parte desses grupos diversos e historicamente oprimidos, quanto para os que negam e reproduzem o racismo em seu cotidiano, dentro e fora da escola. Assim, notamos consenso entre as(os) cursistas ao reconhecerem que sem incluir a "branquitude" nas discussões não é possível construir uma educação antirracista, já que a luta, assim como o reconhecimento e o respeito aos direitos do outro, passa pelo acesso de todos e todas ao conhecimento da diferença como construção cultural e histórica.

Voltamos ao tema da ditadura civil-militar para exemplificar possibilidades interseccionais de abordagem em sala de aula: em Ditadura e homossexualidades. Repressão, resistência e a busca da verdade (2014), James Green e Renan Quinalha mostram como, sob a elástica categoria de "subversão", foram enquadrados como criminosos movimentos e grupos de homossexuais e de negros(as) cujos locais de encontro passaram a ser monitorados e perseguidos. A questão que colocamos era: como sentiram a repressão sujeitos de esquerda, gays ou lésbicas e negras(os)?

No campo das relações e intermediações entre a produção acadêmica e o grande público, apontamos interlocutoras como a Jornalista Eliane Brum (2014), a psicanalista Maria Rita Kehl (2010), e a filósofa Marcia Tiburi (2014), entre muitas outras intelectuais e ativistas de várias áreas que vem incorporando relatos de torturas durante ditaduras para tratar do corpo feminino como campo de batalha na democracia. Destacamos ainda a atuação do Movimento Negro Unificado na luta contra o racismo que permeou a ditadura militar, tendo 
entre seus/suas fundadores(as) a historiadora e filósofa Lélia Gonzalez, uma das precursoras do feminismo negro e introdutoras do debate sobre as conexões de gênero e raça na pauta de ambos movimentos. Entre os movimentos sociais, citamos as Marchas das Vadias ${ }^{4}$, com seus corpos à mostra e com a evidente performance conceitual a respeito dos machismos colonizadores do feminino. Consideramos que as Marchas retomam especialmente bandeiras surgidas nos anos de 1970, de movimentos que também se colocavam como de resistência à ditadura, com destaque para a questão do aborto.

Feito isso, passamos para a última etapa do trabalho, que consistiu na apresentação de propostas de intervenção em sala de aula a partir das questões que foram discutidas durante as duas manhãs de encontro.

\section{Temas-trauma em sala de aula e experiências docentes}

Para efeito deste artigo, em termos de espaço e possibilidade de diálogo, selecionamos uma das atividades que realizamos com o grupo para apresentar. Após um pequeno tempo de elaboração, pedimos que expusessem, individualmente ${ }^{5}$, propostas de abordagem em sala de aula que considerassem pertinentes após toda nossa discussão. O resultado foi o seguinte:

- Professora A: trabalha com terceiro ano do Ensino Médio e sua proposta teve como tema "A questão da Imigração no século XIX. O movimento republicano e abolicionista na história do Brasil”. O objetivo principal era desconstruir a imigração como empreendimento privado de sucesso no Sul do país, discutindo o extermínio indígena e as ideias de civilização e modernidade como elaborações ligadas ao que hoje conhecemos como branquitude. As fontes sugeridas são fotografias de bugreiros e indígenas que mostram crianças indígenas “armazenadas" em casas de imigrantes alemães.

- Professora B: propôs uma aula sobre Racismo e Ensino religioso, com o objetivo de apresentar a historicidade das religiões, apresentando o Deus católico como forma cultural de demonstração de religiosidade. O Racismo seria apreendido também como forma de intolerância religiosa. A dinâmica do encontro seria baseada na escuta das histórias de vida das(os) estudantes, intercalando com intervenções da professora.

$4 \quad$ Para uma perspectiva analítica, sugerimos a tese de Morgani Guzzo, defendida em 2019 no PPGH-UFSC intitulada: "Corpos e campos plurais: os feminismos das marchas das vadias no Brasil".

$5 \quad$ Optamos por não identificar as(os) participantes do minicurso, destacando, para elaboração neste artigo, os temas e impasses mais sensíveis colocados pelas(os) inscritas(os) e diante dos quais nos posicionamos de maneira mais empírica, não encontrando outras referências em experiências pessoais e pedagógicas anteriores. 
- Professora C: ministra aulas para o nono ano do Ensino Fundamental e propôs uma aula sobre a constituição teórica do Racismo como fenômeno criado pelo colonialismo a partir do século XVI. Para tanto, utilizaria caricaturas publicadas em jornais portugueses do século XVIII sobre a África, ou seja, a construção da África pelos olhos europeus e sua justificativa para a colonização. Nessas caricaturas, as pessoas africanas são representadas como animais ou como mulheres. Capítulos de desenhos animados seriam questionados com a ajuda da professora: em um capítulo d'As aventuras de Tintim, por exemplo, africanas(os) falam em português errado e congoleses são representados como crianças. Capítulos de Tarzan e King Kong demonstrariam visões colonialistas de uma África essencialmente selvagem.

- Professora D: apresentou proposta de aula para estudantes do terceiro ano do Ensino Médio com tema central: "Manifestações culturais contra a ditadura militar no Brasill". Como fontes, seriam utilizados capas e vinis de grupos punks dos anos de 1970 que produziram letras críticas ao autoritarismo. Do ponto de vista dos acontecimentos históricos, a professora ressaltou a rixa paulista entre manifestantes do $\mathrm{ABC}$, em sua maioria, de operários, e a capital do estado, onde os protestos foram liderados por estudantes - considerados pelos operários como privilegiados do sistema socioeconômico. Um dos tópicos da aula consistia na "Censura", institucionalizada entre 1972 e 1988. Também foi sugerido o documentário Botinada: A Origem do Punk no Brasil (2006).

As propostas de intervenção mesclam experiências já realizadas, conforme relatos das(dos) cursistas, com as questões debatidas no minicurso. Elas demostram o esforço das(dos) professoras(es) em inserir o que aqui optamos por chamar de temas-trauma, como o racismo, as desigualdades de gênero e de classe nas aulas de história, o que é muito positivo. Entretanto, notamos que tais temas, apesar de nossa insistência, ainda foram abordados de modo separado. Observamos que, das quatro, três inserem o estudo do racismo como problema de investigação (A, B e C). Dessas, em apenas uma foi possível perceber traços de um possível entrecruzamento com as questões de gênero (C). Somente em uma (D), o tema Ditadura Militar foi proposto, problematizando as desigualdades e os conflitos de classe, mas sem fazer qualquer conexão com as categoria "raça" e "gênero". Como não houve tempo para que nós, ministrantes, pudéssemos socializar essas observações, asseguramos que o faríamos através de um artigo assim que nos fosse possível e o enviaríamos a todas(os), retomando nosso contato. 


\section{Considerações}

Após o relato de todo o percurso, chegamos ao fim deste artigo, apresentando algumas considerações que, longe de serem finais, são pontos de partida para outros recomeços.

Consideramos que o minicurso se constituiu como uma experiência valiosa para nós, uma oportunidade de estarmos em contato com os saberes docentes, conhecendo suas práticas, compartilhando inquietações e desafios. O encontro nos possibilitou conhecer profissionais comprometidos em construir uma educação inclusiva, assentada no respeito à diferença e aos direitos humanos.

A experiência, ainda que de curta duração, nos mostrou que há consenso entre os(as) professores(as) de que o tempo presente, e não apenas o passado, é objeto da História. Porém percebemos a necessidade de maior aprofundamento dessas categoriais temporais e de suas relações de coexistência e imbricações em uma mesma temporalidade histórica.

Também ficou visível para nós que há, entre os(as) docentes, um comprometimento com a inserção de temas-trauma nas aulas de História. A própria inscrição e frequência no minicurso, bem como os diálogos e as propostas de intervenção apresentadas, foram reveladoras desse compromisso. Não é possível afirmar, porém, se esta é uma prática permanente ou apenas eventual.

Como vimos, o racismo foi o tema mais abordado nas apresentações. Talvez isto se explique, entre outras coisas, devido ao desenvolvimento de políticas públicas para a educação das relações étnico-raciais adotadas no Brasil desde 2003, as quais ressoam no trabalho dos docentes, ao passo que não foram feitos ainda grandes esforços para uma educação em Direitos Humanos em toda a sua amplitude, incluindo, além do racismo, a luta contra as formas de violência estatal, de gênero, homofobia, etc.

Por fim, percebemos a dificuldade em interseccionalizar as categorias de raça, gênero e classe, daí porque foi preciso reestruturar nosso planejamento para dar maior atenção a esta

questão, sem a qual qualquer tentativa de construção de uma educação antirracista e democrática será incompleta.

Durante todo o processo a proposta esteve aberta e em movimento, sendo constantemente reelaborada a partir das demandas das(os) docentes. Apesar de terem sido apenas oito horas de minicurso, estas corresponderam a momentos intensos de discussão e 
aprendizado, mas que também, como vimos, deixou muitas questões em aberto e muito trabalho por fazer. Assim, este artigo não conclui, visto que as questões apontadas abrem possibilidades para novos encontros e reencontros.

\section{Referências}

AKOTIRENE, Carla. O que é interseccionalidade. Belo Horizonte: Letramento, 2018.

BAUER, Caroline S. "Um estudo comparativo das práticas de desaparecimento nas ditaduras civil-militares argentina e brasileira e a elaboração de políticas de memória em ambos os países". Tese de doutorado defendida na Universidade Federal do Rio Grande do Sul. Instituto de Filosofia e Ciências Humanas. Programa de Pós-Graduação em História, 2011.

BRAGA, Sabrina. C. Testemunho, catástrofe e historiografia: entrevista com Márcio Selgmann-Silva". Revista De Teoria Da História - Journal of Theory of History, 19(1), 297304, 2018.

BRUM, Eliane. "Aos que defendem a volta da ditadura. Eles eram 400 nas ruas de São Paulo, no primeiro sábado de dezembro, pedindo intervenção militar. Quatrocentos não é pouco. Um é muito". El País, 8 de dezembro de 2014.

CARNEIRO, Sueli. Enegrecer o feminismo: a situação da mulher negra na América Latina a partir de uma perspectiva de gênero. In: HOLANDA, Heloísa Buarque de. Pensamento Feminista: conceitos fundamentais. Rio de Janeiro: Bazar do Tempo, 2019.

DELACROIX, Christian. A história do tempo presente, uma história (realmente) como as outras? Tempo e Argumento, Florianópolis, v. 10, n. 23, p. 39 - 79, jan./mar. 2018.

DUARTE, Ana Rita F. (Org.). As mobilizações do gênero pela ditadura militar brasileira. Fortaleza: Expressão Gráfica, 2014.

FRANCO, Marina. La última dictadura argentina en el centro de los debates y las tensiones historiográficas recientes. Tempo e Argumento, Florianópolis, v. 10, n. 23, p. 138-166, jan./mar. 2018.

GIL, Carmem Zeli de Vargas; EUGÊNIO, Jonas Camargo. Ensino de História e temas sensíveis: abordagens teórico-metodológicas. In: História Hoje, v. 7, n. 13, p. 1-21, 2018. Disponível em: http://www.rhh.anpuh.org. Acesso em 01/09/2019.

GÓES, Juliana. Ciência sucessora e a(s) epistemologia(s): saberes localizados. Rev. Estud. Fem. vol. 27 no. 1, Florianópolis, 2019.

GREEN, James; QUINALHA, Renan (Orgs.). Ditadura e homossexualidades. Repressão, resistência e a busca da verdade. São Carlos: Edufscar, 2014.

GUZZO, Morgani. Corpos e campos plurais: os feminismos das marchas das vadias no Brasil. Tese de doutorado defendida no PPGH-UFSC, 2019.

HARAWAY, Donna. Manifesto ciborgue. Ciência, tecnologia e feminismo-socialista no final do século XX. In: HARAWAY, D.; KUNZRU, H.; TADEU, T. Antropologia do ciborgue: as vertigens do pós-humano. Belo Horizonte: Autêntica, 2009, p. 33-118

HARAWAY, Donna. Saberes localizados: a questão da ciência para o feminismo e o privilégio da perspectiva parcial. Cadernos pagu (5) 1995: p. 07-41. 
MBEMBE, Achille. Crítica da razão negra. São Paulo: N-1 edições, 2018.

JOFFILY, Mariana. Aniversários do golpe de 1964: debates historiográficos, implicações políticas. Tempo e Argumento, Florianópolis, v. 10, n. 23, p. 204 - 251, jan./mar. 2018.

KEHL, Maria Rita. "Tortura e sintoma social". In: TELES, Edson; SAFATLE, Vladimir (Orgs.). O que resta da ditadura: a exceção brasileira. São Paulo: Boitempo, 2010. p. 123133.

KILOMBA, Memórias da plantação: episódios de racismo cotidiano. Rio de Janeiro: Cobogò, 2019.

PEREIRA, Nilton Mullet; MEINERZ, Carla Beatriz; PACIEITCH, Caroline. Viver e pensar a docência diante da demandas sociais e identitárias do século XXI. História \& Ensino, Londrina, v. 21, n. 2, p. 31-53, jul./dez. 2015. Disponível em: http://www.uel.br/revistas/uel/index.php/histensino/article/view/23850. Acesso em $27 / 11 / 2018$.

PIRES, Thula Rafaela de Oliveira. Comissão da Verdade do Rio de Janeiro. Relatório de pesquisa. Colorindo memórias e redefinindo olhares: ditadura militar e racismo no Rio de Janeiro. Rio de Janeiro, 10 de agosto de 2015.

RATTS, Alex; RIOS, Flavia M. Lélia Gonzalez: Retratos do Brasil Negro. São Paulo: Summus/Selo Negro, 2010, 173 p.

ROUSSO, Henry. A última catástrofe: a história, o presente, o contemporâneo. Trad. Fernando Coelho e Fabrício Coelho. Rio de Janeiro: FGV, 2016.

SCOTT, Joan. "Gênero: uma categoria útil de análise histórica". Educação e Realidade. 20(2): 78-99; 1995.

TIBURI, Marcia; BORGES, Maria de Lourdes (Orgs). Filosofia: machismos e feminismos. Florianópolis, Ed. da UFSC, 2014.

VILLA, Marco Antônio. Ditadura à brasileira, Folha de S. Paulo, 5 mar. 2009. 